
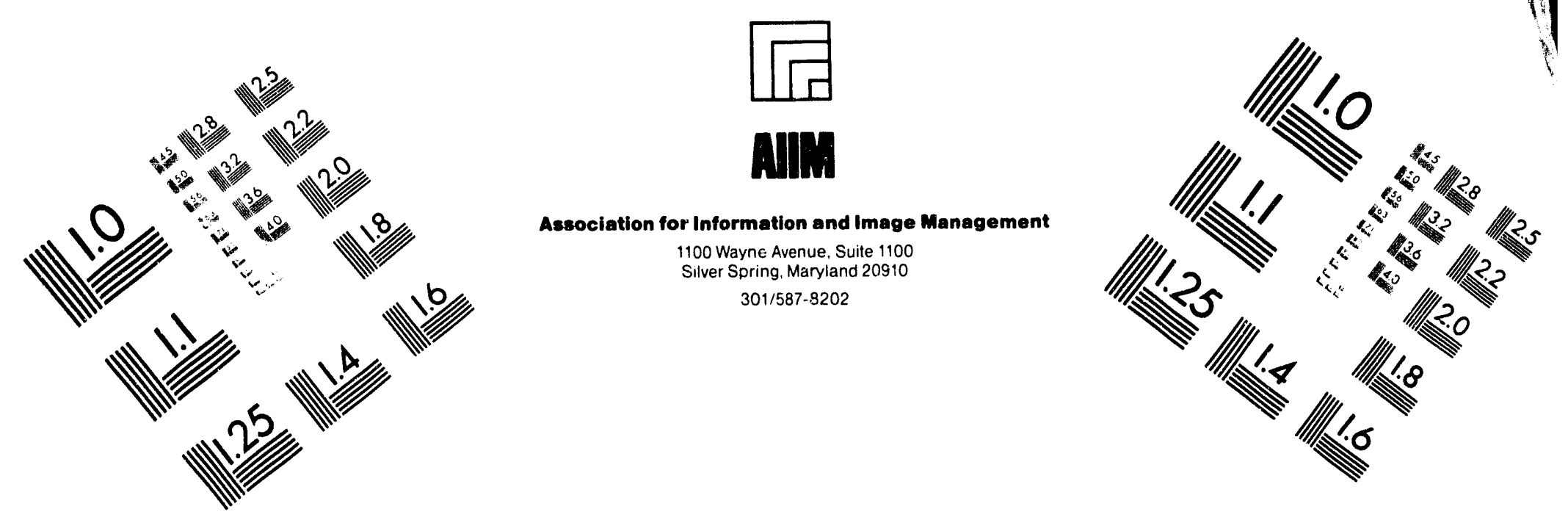

Centimeter


Inches
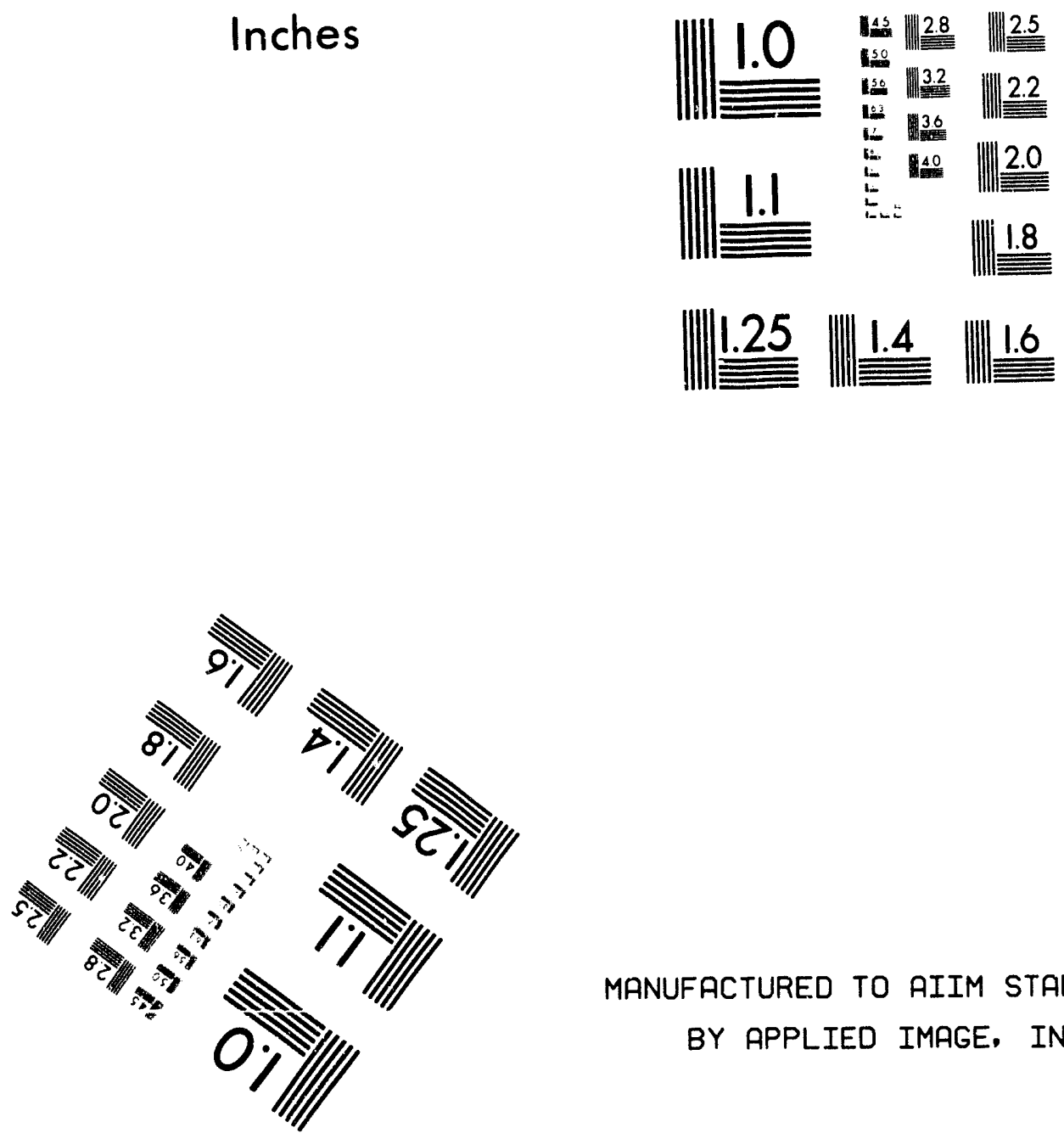

MANUFACTURED TO AIIM STANDARDS

BY APPLIED IMAGE, INC.

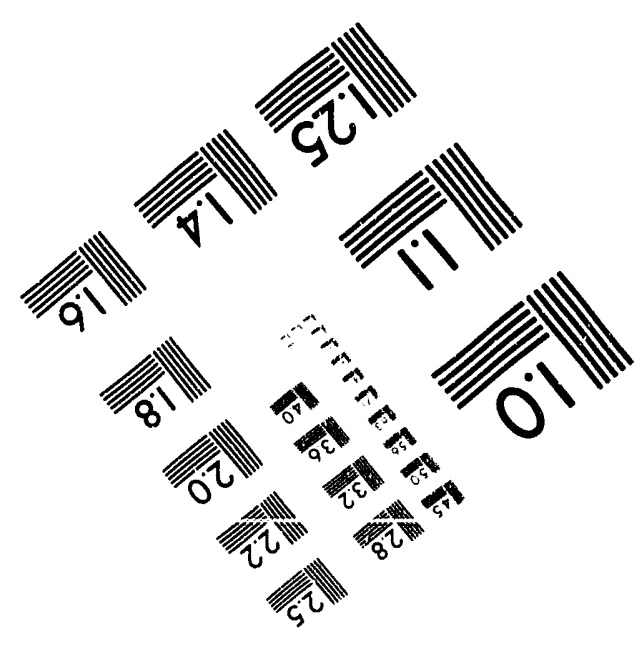



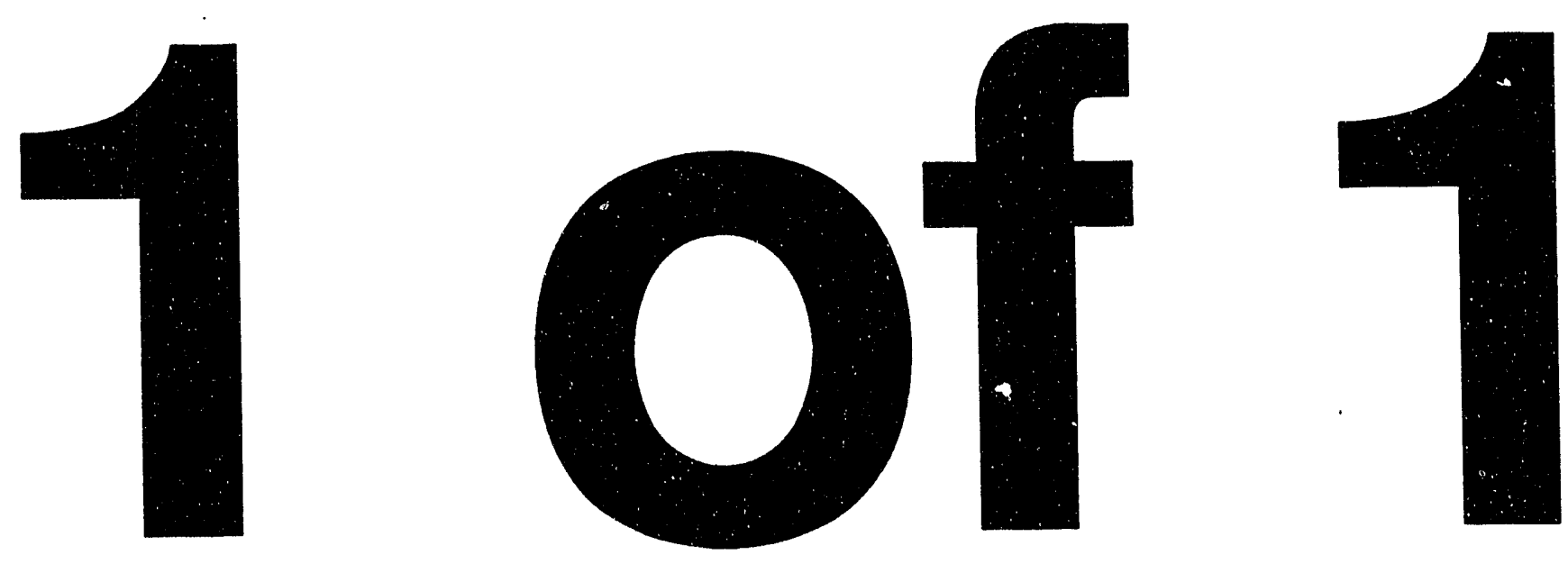


\section{A NOVEL APPROACH TO MODELING UNSTABLE EOR DISPLACEMENTS}

Quarterly Report for the Period

January 1993 - March 1993

Contract No. DE-AC22-90BC14650

The University of Texas at Austin

Austin. Texas

Contract Date: August 28, 1990

Anticipated Completion: August 27, 1993

Government Award: \$407,118 (Current Year)

Principal Investigator:

Ekwere J. Peters

Contracting Officer Representarive:

Jerry D. Ham

Metairie Site Office

900 Commerce Road, East

New Orleans, LA 70123

Prepared by

The University of Texas

Department of Petroleum Engineering

Austin. TX 78712

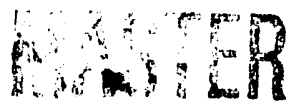

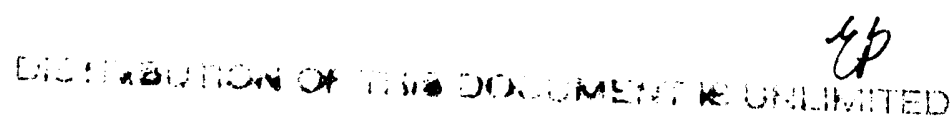




\section{OBJECTIVES}

This research is aimed at developing a methodology for predicting the performance of unstable displacements in heterogeneous reservoirs. A performance prediction approach that combines numerical modeling with laboratory imaging experiments is being developed.

Flow visualization experiments are being performed on laboratory corefloods using $\mathrm{X}$-ray Computed Tomography (CT) and other imaging technologies to map the insitu fluid saturations in time and space. A systematic procedure is being developed to replicate the experimental image data with high-resolution numerical models of the displacements. The well-tuned models will then be used to scale the results of the laboratory coreflood experiments to heterogeneous reservoirs in order to predict the performance of unstable displacements in such reservoirs.

\section{SUMMARY OF TECHNICAL PROGRESS}

Previous reports have concentrated on the problem of modeling unstable immiscible displacements in heterngeneous porous media (Peters 1992a, Peters 1992b and Peters, lyyı,. In this report, we begin the examination of the problem of modeling miscible displacements. A miscible displacement is the most desirable type of displacement in enhanced oil recovery because there is no interfacial tension between the fluids and therefore no capillary trapping of the fluids. Thus, in a miscible displacement, it is possible to recover $100 \%$ of the oil in the areas contacted by the injected solvent.

There are four major issues in miscible displacements. The first issue is the quantitative description of the mixing or dispersion that occurs in miscible displacements and the attendant problem of measuring the dispersion coefficient for the porous medium. The second issue is the problem of hydrodynamic instability. Because the solvent is nearly always less viscous and less dense than the oil, instabilities in the forms of viscous fingering and gravity override frequently occur in miscible displacements. These instabilities reduce process efficiency and complicate process modeling and prediction. The third issue is the impact of heterogeneity on the performance of miscible displacements. Because natural reservoirs are nearly always heterogeneous at different length scales, the impact of heterogeneity on the performance of unstable miscible displacements is of practical significance. The fourth and final issue is process optimization and economics. Because the injected solvents are more expensive than the oil to be displaced, they must be injected in small quantities as slugs and chased by less expensive fluids to make the project economically feasible. What is the optimum slug size that will prevent complete degradation of the slug by mixing caused by dispersion, instabilities and heterogeneity? The first three issues are addressed in this research. The fourth issue is outside the scope of this research.

In this report, we address the first issue-the description of dispersion in porous media. We present an improved method to measure the longitudinal dispersion coefficient of a porous medium from CT imaging of a tracer test in the medium. The method is demonstrated by measuring the dispersion coetficients for a sandpack and a Berea sandstone. Imaging the tracer test allows the effects of dispersion and heterogeneity to be distinguished.

\section{Theory}

In order to focus attention on the dispersion phenomenon, we consider a tracer test consisting of a stable, first-contact miscible displacement of two incompressible fluids having equal viscosities and densities in a homogeneous porous medium. For such a displacement, viscous and gravity instabilities are suppressed and only dispersion will manifest itself. The mathematical model for this displacement in one dimension consists of the continuity equation, Darcy's law and the convection-dispersion equation: 


$$
\begin{gathered}
\frac{\partial u}{\partial x}=0 \\
u=-\frac{k}{\mu} \frac{\partial P}{\partial x} \\
\frac{\partial C}{\partial t}+\frac{v}{R_{f}} \frac{\partial C}{\partial x}-\frac{D_{L}}{R_{f}} \frac{\partial^{2} C}{\partial x^{2}}=0
\end{gathered}
$$

In the above equations, $u$ is the superficial velocity (Darcy velocity), $v$ is the interstitial velocity $(u / \phi)$ and $R_{f}$ is a retardation factor that accounts for the adsorption of the tracer by the porous medium. If there is no adsorption of the tracer by the porous medium, the retardation factor is unity whereas if there is adsorption, the retardation factor is greater than unity. It can be seen from Eq. 3 that the effect of the retardation factor is to reduce $v$ and the $D_{L}$ for the displacement. Thus, the speed of the solvent concentration is retarded by adsorption.

For a constant rate injection, Eqs. 1 and 2 lead to the following solution for the superficial velocity

$$
\mathrm{u}=\frac{\mathrm{k}}{\mu} \frac{\Delta \mathrm{P}}{\mathrm{L}}=\mathrm{a} \text { constant }
$$

where $\Delta \mathrm{P}$ is the pressure drop across the porous medium and $\mathrm{L}$ is the length of the porous medium. Therefore, the interstitial velocity is given by

$$
v=\frac{\mathrm{u}}{\phi}=\frac{\mathrm{k}}{\mu} \frac{\Delta \mathrm{P}}{\phi \mathrm{L}}=\mathrm{a} \text { constant }
$$

Equation 5 can then be substituted into Eq. 3 to describe the longitudinal dispersion of the solvent in the porous medium. To solve Eq. 3 for the case of continuous injection of the solvent, we apply the following initial and boundary conditions:

$$
\begin{array}{ll}
C(x, 0)=0 & x>0 \\
C(0, t)=C_{0} & t \geq 0 \\
C(\infty, t)=0 & t \geq 0
\end{array}
$$

The analytical solution to Eq. 3 for the initial and boundary conditions given by Eqs. 6 to 8 is (Ogata and Banks, 1961)

$$
C(x, t)=\frac{C_{0}}{2}\left[\operatorname{erfc}\left(\frac{x-\left(v / R_{f}\right) t}{2 \sqrt{\left(D_{I} / R_{f}\right) t}}\right)+\exp \left(\frac{v x}{D_{L}}\right) \operatorname{erfc}\left(\frac{x+\left(v / R_{f}\right) t}{2 \sqrt{\left(D_{V} / R_{f}\right) t}}\right)\right]
$$

where erfc is the complementary error function, an integral that is tabulated in mathematical handbooks. An approximate analytical solution normally used to determine the dispersion coefficient from breakthrough data is 


$$
C(x, t)=\frac{C_{0}}{2}\left[\operatorname{erfc}\left(\frac{x-\left(v / R_{f}\right) t}{2 \sqrt{\left(D_{V} \sqrt{R_{f}}\right) t}}\right)\right]
$$

In dimensionless form, Eq. 10 becomes

$$
C\left(x_{D}, t_{D}\right)=\frac{C_{0}}{2}\left\{\operatorname{erfc}\left[\sqrt{N_{P e}}\left(\frac{x_{D}-\left(t_{D} / R_{f}\right)}{\sqrt{t_{D} / R_{f}}}\right)\right]\right\}
$$

where the dimensionless variables are defined as

$$
\begin{aligned}
x_{D} & =\frac{x}{L} \\
t_{D} & =\frac{v t}{L} \\
N_{P e} & =\frac{v L}{D_{L}}
\end{aligned}
$$

Equation 15 defines a Peclet number which is the ratio of convective to dispersive transports. Eq. 11 suggesis a self-similarity transformation variable for first-iontact miscible displacement of the form

$$
\xi=\frac{x_{D}-\left|\frac{t_{D}}{R_{f}}\right|}{\sqrt{\frac{t_{D}}{R_{f}}}}
$$

Defining a mixing zone length as the distance between $C=0.1$ and $C=0.9$, it can be shown from Eq. 11 that the growth of the mixing zone is given in dimensionless form by (Lake, 1989)

$$
\Delta x_{D}=3.625 \sqrt{\frac{I_{D}}{N_{P_{C}} R_{f}}}
$$

or in dimensional form by

$$
\Delta x=3.625 \sqrt{\frac{D_{L} t}{R_{f}}}
$$

Thus, by measuring the length of the mixing zone as a function of time, Eq. 17 can be used to calculate the longitudinal dispersion coefficient for the porous medium. The length of the mixing zone can easily be measured by imaging the experiment.

The longitudinal dispersion coefficient consists of a diffusion and a mechanical dispersion term, as shown in the following equation (Perkins and Johnston, 1963):

$$
D_{L}=\frac{D_{0}}{F \phi}+\alpha_{L} v
$$

In Eq. $18, D_{0}$ is the molecular diffusion coefficient, $F$ is the formation electrical resistivity factor, $\phi$ is the porosity, and $\alpha_{\mathrm{L}}$ is the longitudinal dispersivity. At interstitial velocities greater than about $3.5 \times 10^{-5} \mathrm{~cm} / \mathrm{s}$, the mechanical dispersion term $\left(\alpha_{L} v\right)$ dominates the molecular diffusion term $\left(D_{0} / F \phi\right)$ (Lake and Hirasaki, 1981). Therefore, at a sufficiently 
high displacement rate or Peclet number, Eq. 18 can be used to estimate the longitudinal dispersivity from the dispersion coefficient by neglecting the molecular diffusion term.

Assuming a linear sorption isotherm, the retardation factor is related to the distribution coefficient, $\mathrm{K}_{\mathrm{d}}$, as (Domenico and Schwartz, 1990):

$$
R_{f}=\left[1+\frac{(1-\phi)}{\phi} \rho_{s} K_{d}\right]
$$

from which the distribution coefficient can be determined.

\section{Experiments}

Traditionally, the longitudinal dispersion coefficient is normally determined by measuring the solvent concentration at the outlet end of the porous medium for a tracer test and then applying Eq. 11 at the outlet end to calculate $D_{L}$ or more correctly $D_{L} / R_{f}$ if retardation is not explicitly accounted for. This method gives an average $D_{L}$ that includes the effects of hydrodynamic dispersion and heterogeneity. We present herein a method of determining $D_{L}$ that allows the effects of dispersion and heterogeneity to be distinguished. This is accomplished by imaging the tracer test experiment in time and space. We use Eq. 11 to determine the average $D_{L}$ (due to dispersion and heterogeneity) and $\mathrm{R}_{\mathrm{f}}$ by historymatching the average concentration profiles and use Eq. 17 to determine the component of $D_{L}$ that is due to dispersion only by measuring the length of the mixing zone with time from the image data.

To demonstrate our method, two tracer tests were performed and imaged by CT. The first test was in an unconsolidated sandpack wherecis the second test was in a consolidated Berea sandstone. In the tracer tests, brine containing an X-ray contrast agent was used to displace or was displaced by another brine of the same viscosity and density. The experiments were designed to approximate a one-dimensional displacement in accordance with the theoretical derivations given above. Table 1 shows the pertinent experimental parameters.

\section{Results and Discussion}

Figure 1 shows the solvent concentration images for the tracer test in the sandpack at $0.2,0.5$ and 0.9 pore volumes injected. The images show a vertical slice through the center of the sandpack. The growth of the mixing zone with distance or injection time is apparent. The distortion in the mixing zone is caused by inhomogeneities in the sandpack. Such distortions or heterogeneities serve to increase the average dispersion coefficient measured by the traditional breakthrough curve method.

Figure 2 compares the experimental and calculated solvent concentration profiles based on Eq. 11 using an average longitudinal dispersion coefficient of $100 \times 10^{-5} \mathrm{~cm}^{2} / \mathrm{s}$ and a retardation factor of unity. It is seen that the agreement between the experimental and calculated profiles is good at early times but poor at late times. At late times, the calculated profiles traveled farther than the experimental profiles. However, the experimental and calculated profiles are essentially parallel at late times, indicating that the average longitudinal aispersion coefficient is correct but the retardation factor of unit' is incorrect. Figure 3 compares of the experimental and calculated profiles with the same average dispersion coefficient but with a retardation factor of 1.04 . The agreement between the experiment and Eq. 11 is good at all time steps. It should be noted that the dispersion coefficient estimated from the average solvent concentration protiles contains the effect of heterogeneity in the sandpack and is equivalent to the dispersion coefficient that would be obtained with a breakthrough curve. The average dispersivity for the sandpack was estimated to be $0.098 \mathrm{~cm}$. 
Figure 4 shows the growth of the mixing zone length with time for the sandpack experiment. The average mixing zone length at each time step was measured from the threedimensional CT images of the tracer test. Thus, the effect of the distortion of the mixing zone caused by heterogeneity in the sandpack was excluded from the mixing zone length. It can be seen that the mixing zone grows linearly with the square root of time as predicted by Eq. 16 or 17 . From the slope of the straight line of Figure $4, D_{L} / R_{f}$ was calculated to be $78.5 \times 10^{-5} \mathrm{~cm}^{2} / \mathrm{s}$. Thus, the dispersion coufficient without the effect of heterogeneity in the packing is $82 \times 10^{-5} \mathrm{~cm}^{2} / \mathrm{s}$. Therefore, heterogeneity accounts for about $18 \%$ of the total dispersivity of the sandpack.

Figure 5 shows the solvent concentration images for the tracer test in the Berea sandstone at $0.2,0.5$ and 0.8 pore volumes injected. As in the sandpack, the growth of the mixing zone with distance or injection time is apparent. The distortion in the mixing zone is caused by heterogeneity in the sandstone. The lower half of the sandstone was more permeable than the upper half.

Figure 6 compares the experimental and calculated solvent concentration profiles based on Eq. 11 using an average dispersion coefficient of $600 \times 10^{-5} \mathrm{~cm}^{2} / \mathrm{s}$ and a retardation factor of unity. It is seen that the calculated profiles travel farther than the experimental profiles at all time steps, the separation of the two profiles increasing with time. The results indicate a satisfactory average dispersion coefficient but an incorrect retardation factor. Figure 7 compares the experimental and calculated profiles with the same dispersion coefficient but with a retardation factor of 1.11 The agreement between the experiment and Eq. 11 is excellent at all time steps. The average dispersivity for the Berea sandstone was estimated to be $0.379 \mathrm{~cm}$.

Figure 8 shows the growth of the mixing zone length with time for the Berea sandstone experiment. It can be seen that the mixing zone grows linearly with the square root of time as predicted by Eq. 16 or 17. From the slope of the straight line of Figure 8, $D_{L} / R_{f}$ was calculated to be $388 \times 10^{-5} \mathrm{~cm}^{2} / \mathrm{s}$. Thus, the dispersion coefficient without the effect of heterogeneity in the porous medium is $431 \times 10^{-5} \mathrm{~cm}^{2} / \mathrm{s}$. Therefore, heterogeneity accounts for abou: $28 \%$ of the total dispersivity of the sandstone.

Table 2 summarizes the results for the sandpack and the Berea sandstone. As may be expected, the Berea sandstone which is a natural porous medium has a higher dispersion coefficient (dispersivity) and a higher retardation factor than the clean sandpack. The effect of heterogeneities is to increase the average dispersion coetficient over that which would be obtained in a homogeneous medium.

Figure 9 shows the solvent concentration data at all time steps for the two experiments plotted against the self-similarity variable. As expected from Eq.11, the data transform into unique dimensionless response functions characteristic of the two miscible displacements. The curve for the sandpack is steeper than for the sandstone, a reflection of the higher Peclet number in the sandpack experiment $(\mathrm{NPe}=554)$ than in the sandstone experiment $(\mathrm{NPe}=159)$.

\section{Concluding Remarks}

In this report, we have addressed the problem of describing the mixing or dispersion that occurs in first-contact miscible displacements. A technique based on CT imaging was presented to simultaneously determine the longitudinal dispersion coefficient and the retardation factor for a porous medium. The technique allows the effect of heterogeneity on the dispersion coefficient to be estimated. The method was demonstrated by determining the dispersion coeffïcients (dispersivities) and retardation factors for an unconsolidated sandpack and a consolidated Berea sandstone. The estimated parameters are useful for modeling firstcontait miscible displacements at the laboratory scale. In the next report. we will examine the problem of hydrodynamic instabilities in miscible displacements. 


\section{NOMENCLATURE}

$C=$ Solvent concentration
$C_{0}=$ Inlet solvent concentration
$D_{\mathrm{L}}=$ Longitudinal dispersion coefficient
$\mathrm{D}_{\mathrm{O}}=$ Molecular diffusion coefficient
$\mathrm{F}=$ Formation electrical resistivity factor
$\mathrm{K}_{\mathrm{d}}=$ Distribution coefficient
$\mathrm{NPe}=$ Peclet number
$\mathrm{R}_{\mathrm{f}}=$ Retardation factor
$\mathrm{t}=$ Time
$\mathrm{t} D=$ Dimensionless time
$\mathrm{u}=$ Darcy velocity
$\mathrm{V}=$ Interstitial velocity
$\mathrm{x}=$ Lon titudinal coordinate $_{\mathrm{X}}=$ Dimensionless longitudinal coordinate

\section{Greek Symbols}

$\alpha_{L}=$ Longitudinal dispersivity
$\Delta P=$ Pressure drop
$\rho_{S}=$ Grain density
$\phi=$ Porosity
$\mu=$ Viscosity
$\xi=$ Self-similarity variable

\section{REFERENCES}

Domenico, P.A. and F.W. Schwartz: Physical and Chemical Hydrogeology, John Wiley and Sons, New York (1990).

Lake, L.W.: Enhanced Oil Recovery, Prentice Hall, New Jersey, 1989.

Lake, L.W. and G.J. Hirasaki: "Taylor's Dispersion in Stratified Porous Media." Soc. Pet. Eng. J. (August 1981) 21, 459-65.

Perkins, T.K. and O.C. Johnston "A Review of Diffusion and Dispersion in Porous Media." Soc. Pet. Eng.J. (March 1963) 21, 70-80.

Ogata, A. and R.B. Banks: "A Solution of the Differential Equation of Longitudinal Dispersion in Porous Media," U.S.Geological Survey Professional Paper 411-A, 1961.

Peters, E.J.: “A Novel Approach to Modeling Unstable EOR Displacements," DOE Quarterly Report. January - March. 1992.

Peters, E.J.: "A Novel Approach to Modeling Unstable EOR Displacements," DOE Quarterly Report. April - June, 1992.

Peters, E.J.: "A Novel Approach to Modeling Unstable EOR Displacements," DOE Quarterly Report. July - September, 1992. 
TABLE 1

EXPERIMENTAL CONDITIONS FOR TRACER TEST

\begin{tabular}{|c|c|c|}
\hline \multirow[b]{2}{*}{ Porous Medium } & Experiment 1 & Experiment 2 \\
\hline & & \\
\hline Type & Unconsolidated Sandpack & Berea Sandstone \\
\hline Length $(\mathrm{vm})$ & 54.2 & 60.2 \\
\hline Diameter $(\mathrm{cm})$ & 4.8 & 5.1 \\
\hline Absolute Permeability (Darcies) & 6.4 & 0.160 \\
\hline Average Porosity from CT (\%) & 29.7 & 17.3 \\
\hline \multicolumn{3}{|l|}{ Fluids } \\
\hline Displacing Fluid & Distilled Water $+13 \% \mathrm{NaCl}$ & Distilled Water $+10 \% \mathrm{NaI}$ \\
\hline Density of Displacing Fluid $\left(\mathrm{g} / \mathrm{cm}^{3}\right)$ & 1.089 & 1.078 \\
\hline Viscosity of Displacing Fluid (mPa.s) & 1.262 & 1.029 \\
\hline Displaced Fluid & Distilled Water $+10 \% \mathrm{BaCl}_{2}$ & $\begin{array}{l}\text { Distilled Water }+1.4 \% \\
\mathrm{NaCl}+10 \% \mathrm{KCl}\end{array}$ \\
\hline Density of Displaced Fluid $\left(\mathrm{g} / \mathrm{cm}^{3}\right)$ & 1.089 & 1.078 \\
\hline Viscosity of Displaced Fluid (mPa.s) & 1.127 & 1.028 \\
\hline Viscosity Ratio & 0.9 & 1.0 \\
\hline Darcy Velocity $(\mathrm{cm} / \mathrm{s})$ & $3.037 \times 10^{-3}$ & $2.742 \times 10^{-3}$ \\
\hline Interstitial Velocity $(\mathrm{cm} / \mathrm{s})$ & $1.023 \times 10^{-2}$ & $1.714 \times 10^{-2}$ \\
\hline Breakthrough Recovery (\%) & 95.0 & 84.4 \\
\hline
\end{tabular}


TABLE 2

SUMMARY OF RESULTS

\begin{tabular}{|c|c|c|}
\hline & Experiment 1 & Experiment 2 \\
\hline Porous Medium & $\begin{array}{l}\text { Unconsolidated } \\
\text { Sandpack }\end{array}$ & Berea Sandstone \\
\hline $\begin{array}{l}\text { Longitudinal Dispersion Coefficient with } \\
\text { Heterogeneity }\left(\mathrm{cm}^{2} / \mathrm{s}\right)\end{array}$ & $100 \times 10^{-5}$ & $600 \times 10^{-5}$ \\
\hline $\begin{array}{l}\text { Longitudinal Dispersivity with } \\
\text { Heterogeneity }(\mathrm{cm})\end{array}$ & 0.098 & 0.379 \\
\hline $\begin{array}{l}\text { Longitudinal Dispersion Coefficient without } \\
\text { Heterogeneity }\left(\mathrm{cm}^{2} / \mathrm{s}\right)\end{array}$ & $82 \times 10^{-5}$ & $431 \times 10^{-5}$ \\
\hline $\begin{array}{l}\text { Longitudinal Dispersivity without } \\
\text { Heterogeneity }(\mathrm{cm})\end{array}$ & 0.080 & 0.272 \\
\hline Distribution Coefficient $\left(\mathrm{cm}^{3} / \mathrm{g}\right)$ & 0.0057 & 0.0087 \\
\hline Retardation Factor & 1.04 & 1.11 \\
\hline Peclet Number & 554 & 159 \\
\hline
\end{tabular}




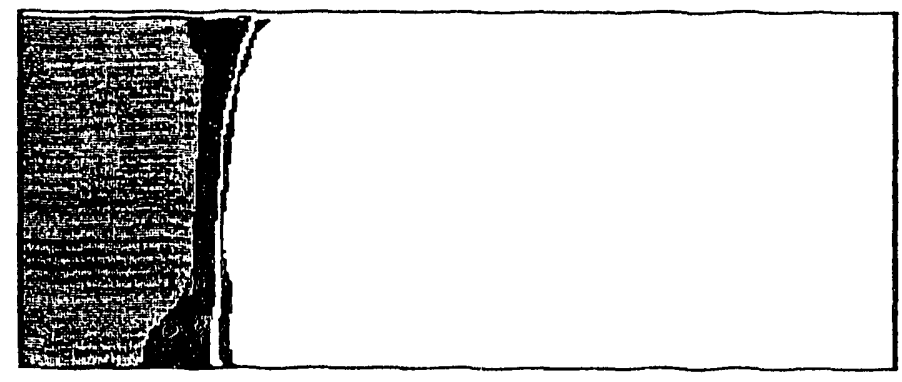

A

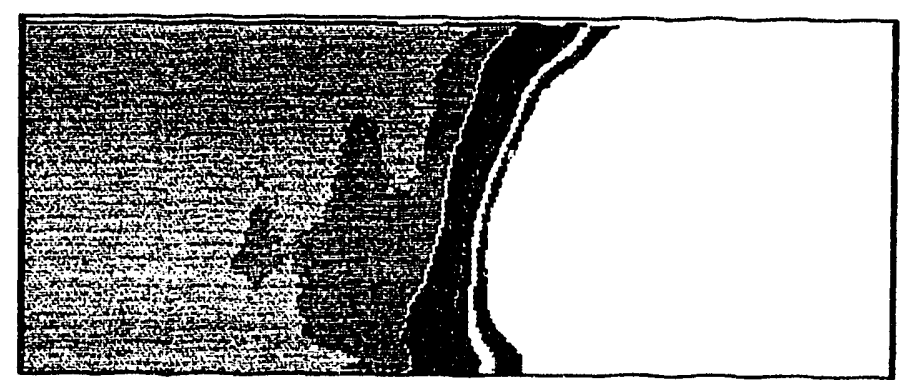

B

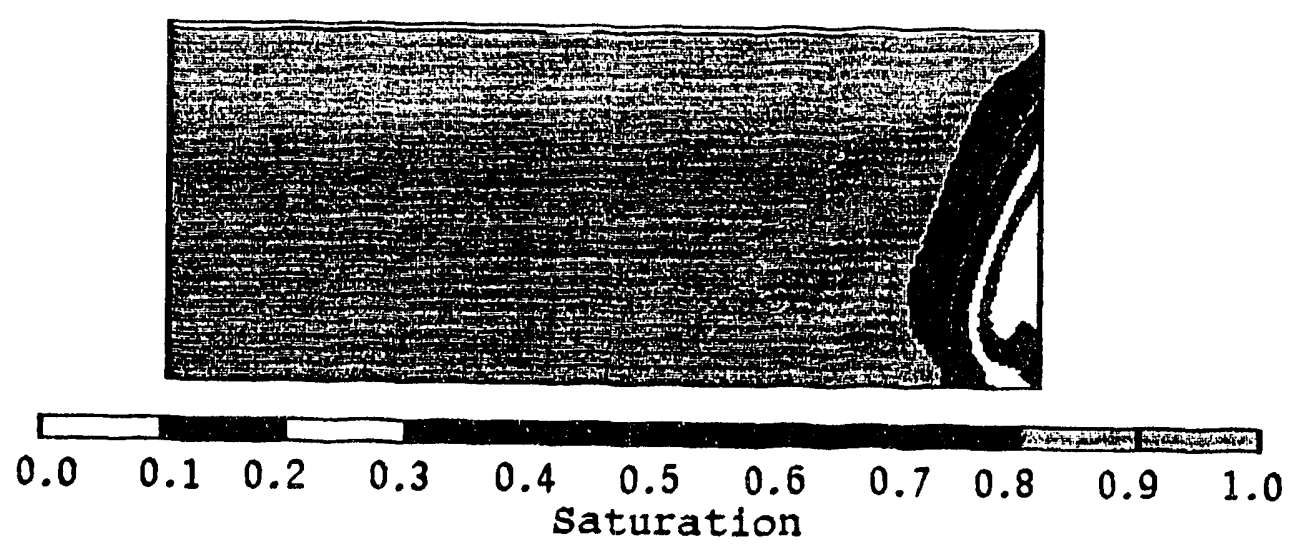

C

Figure 1. Solvent Concentration Images for a Tracer Test in a Sandpack
A. 0.2 Pore Volume Injected
B. 0.5 Pore Volume Injected
C. 0.9 Pore Volume Injected 


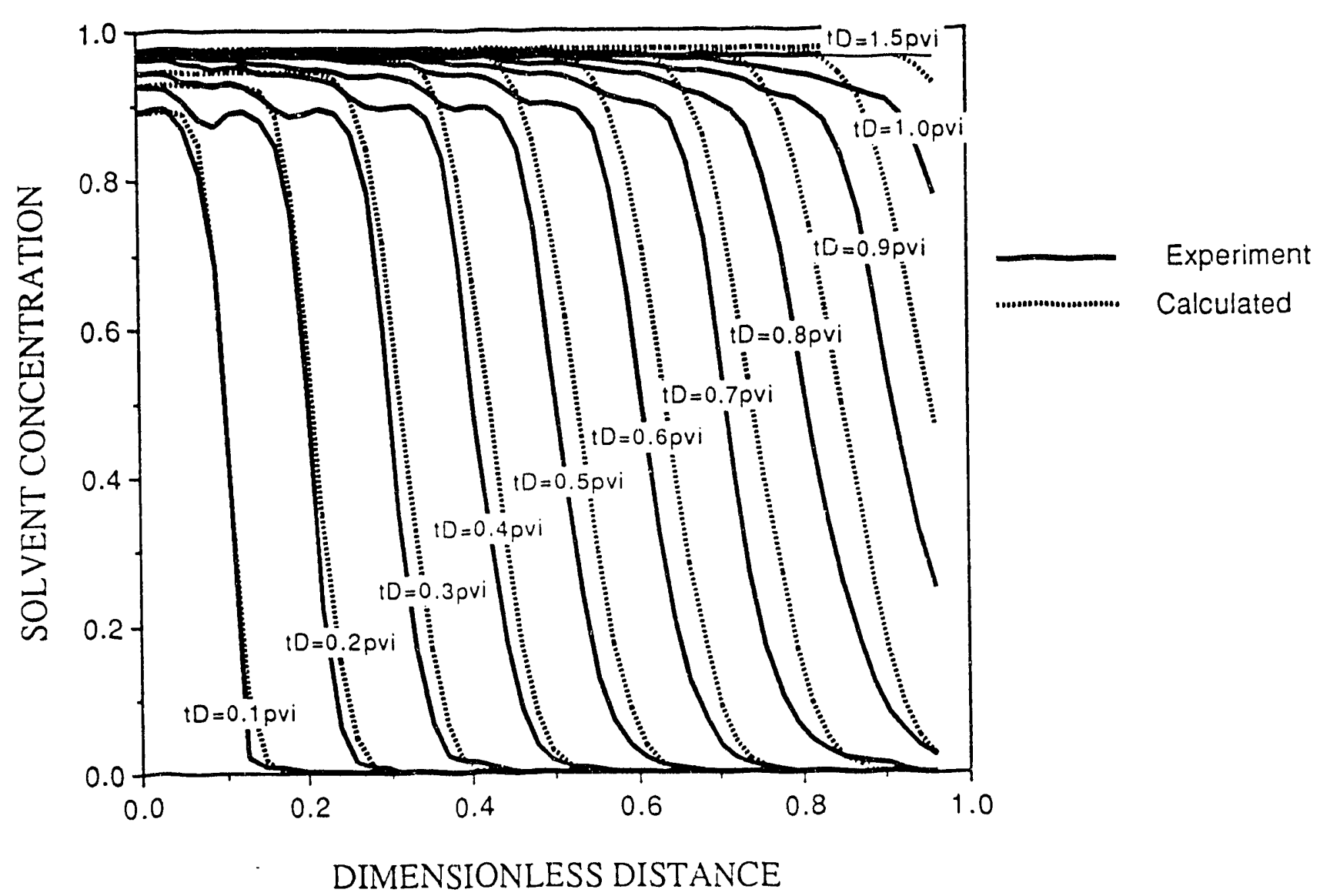

Figure 2. Experimental Versus Computed Solvent Concentration Profiles for Tracer Test in a Sandpack. $D_{\mathrm{L}}=100 \times 10^{-5} \mathrm{~cm}^{2} / \mathrm{s}, \mathrm{R}_{\mathrm{f}}=1.00$ 


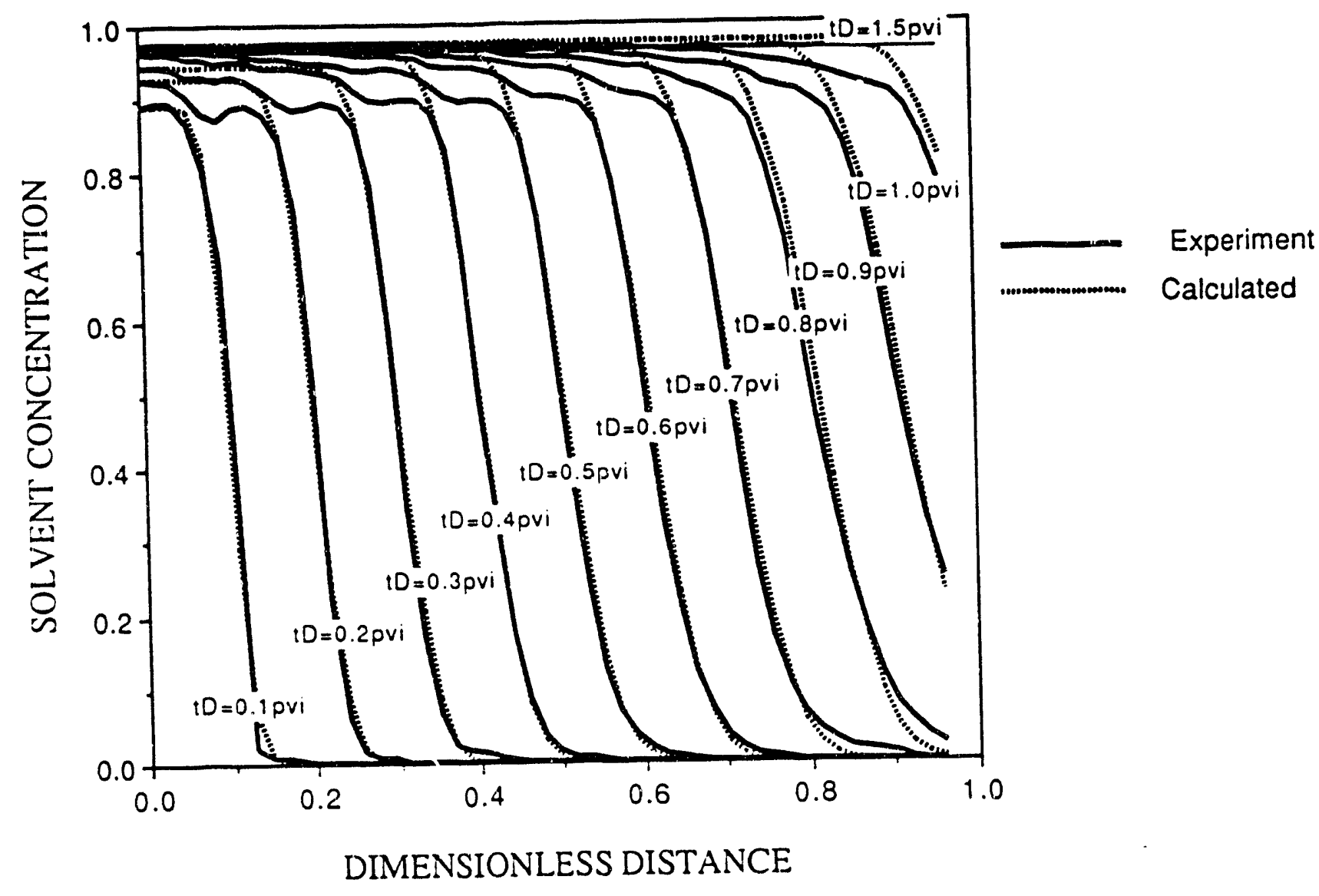

Figure 3. Experimental Versus Compured Solvent Concentration Profiles for Trace: Test in a Sandpack. $D_{L}=100 \times 10^{-5} \mathrm{~cm}^{2} / \mathrm{s}, R_{f}=1.04$ 


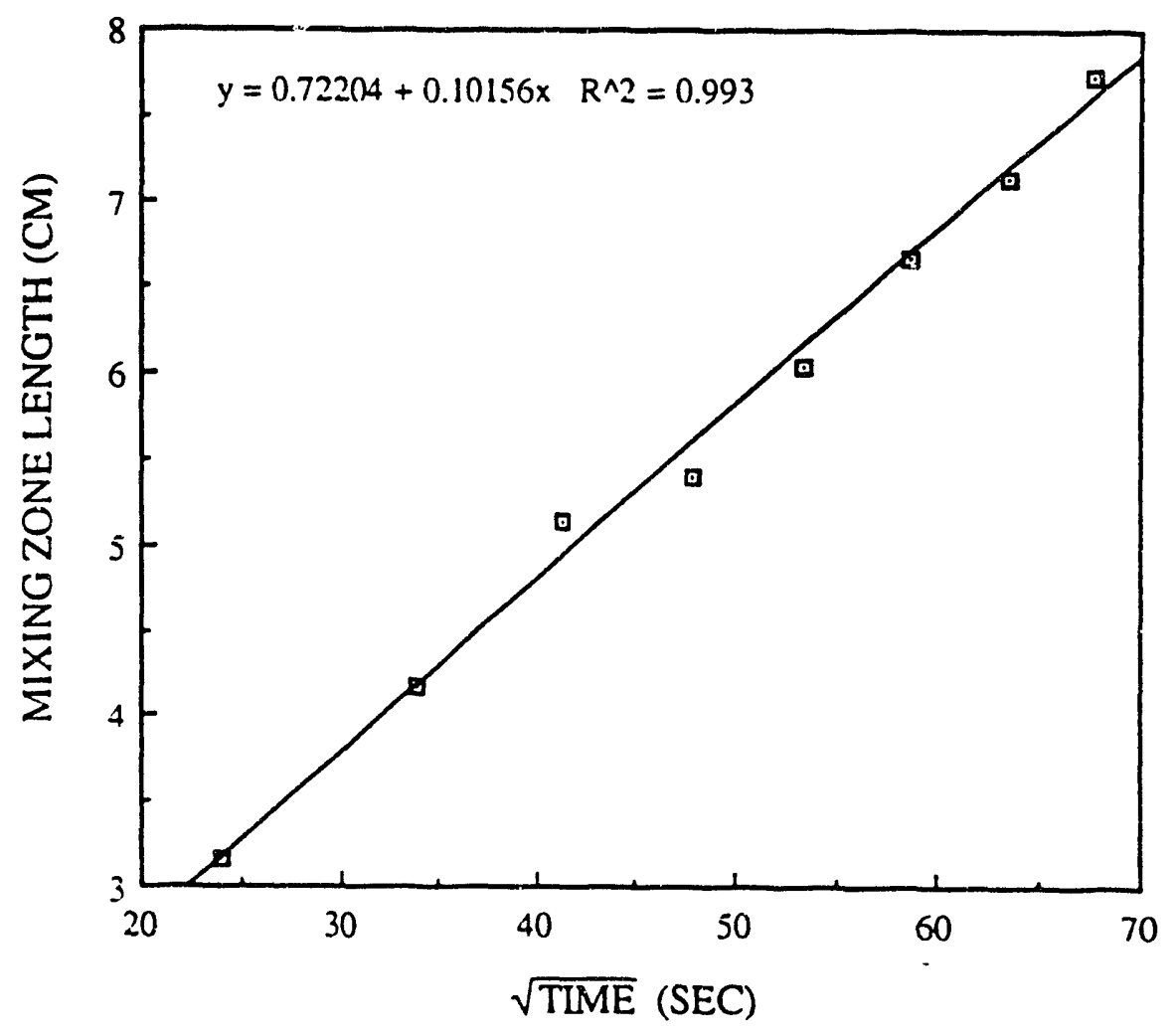

Figure 4. Growth of Mixing Zone Length with Time for a Tracer Test in a Sandpack 


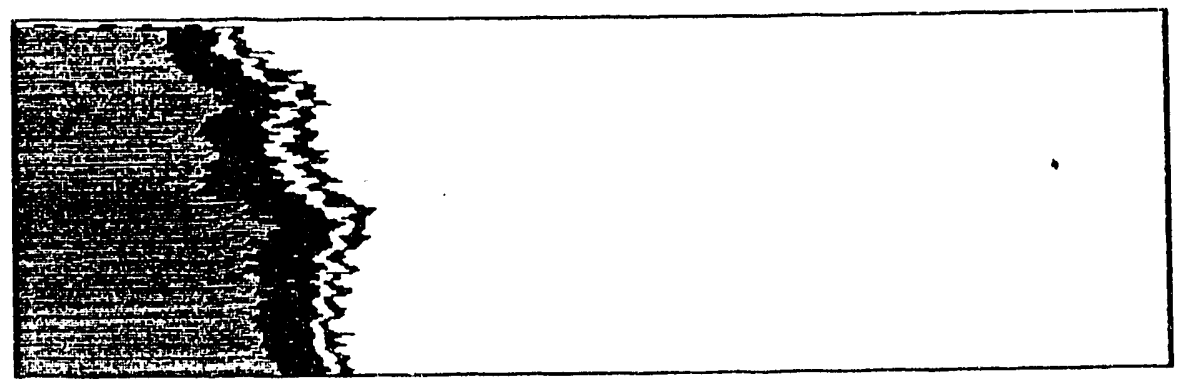

A

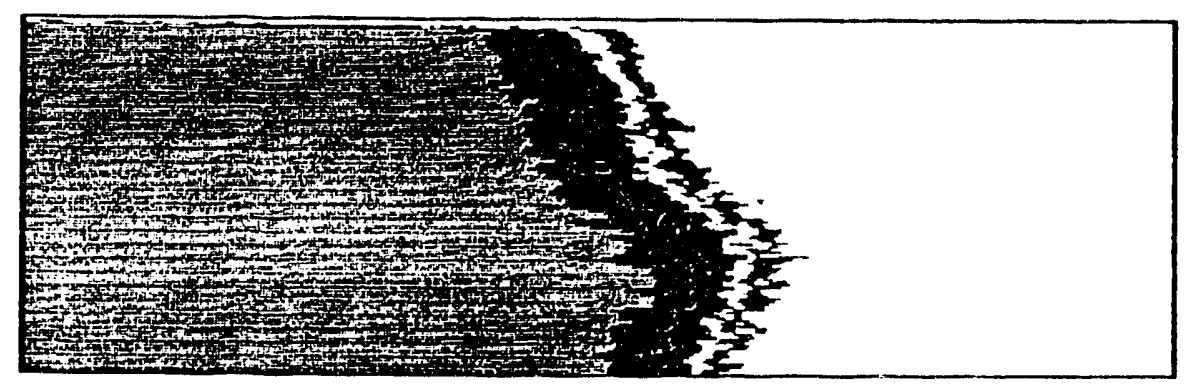

B
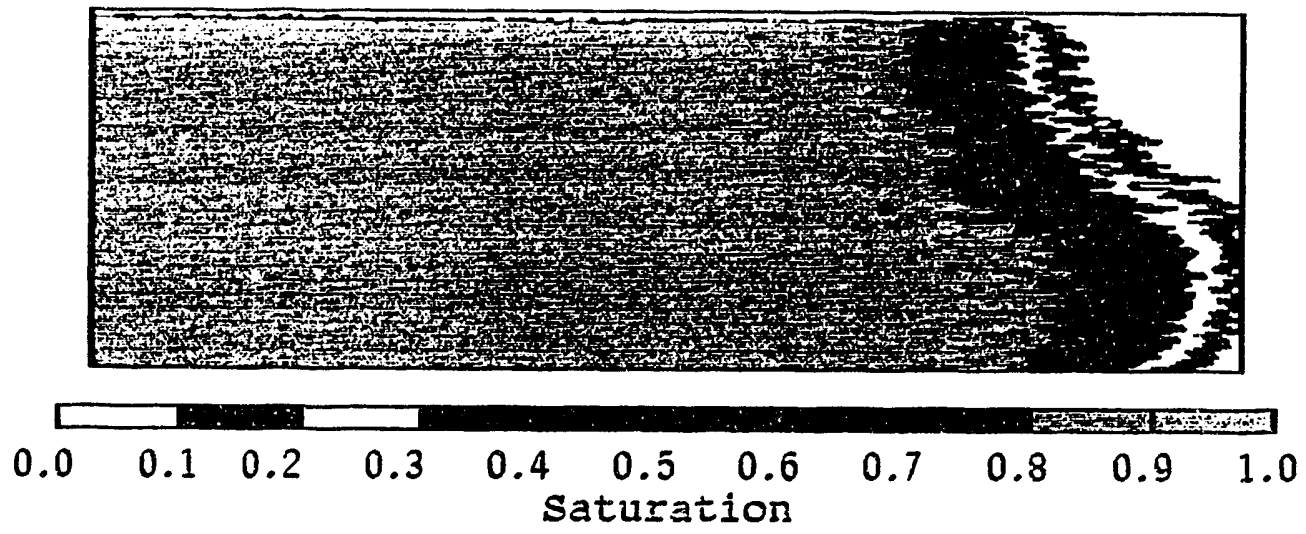

C

Figure 5. Solvent Concentration Images for a Tracer

Test in a Berea Sandstone

A. 0.2 Pore Volume Injected

B. 0.5 Pore Volume Injected

C. 0.8 Pore Volume Injected 


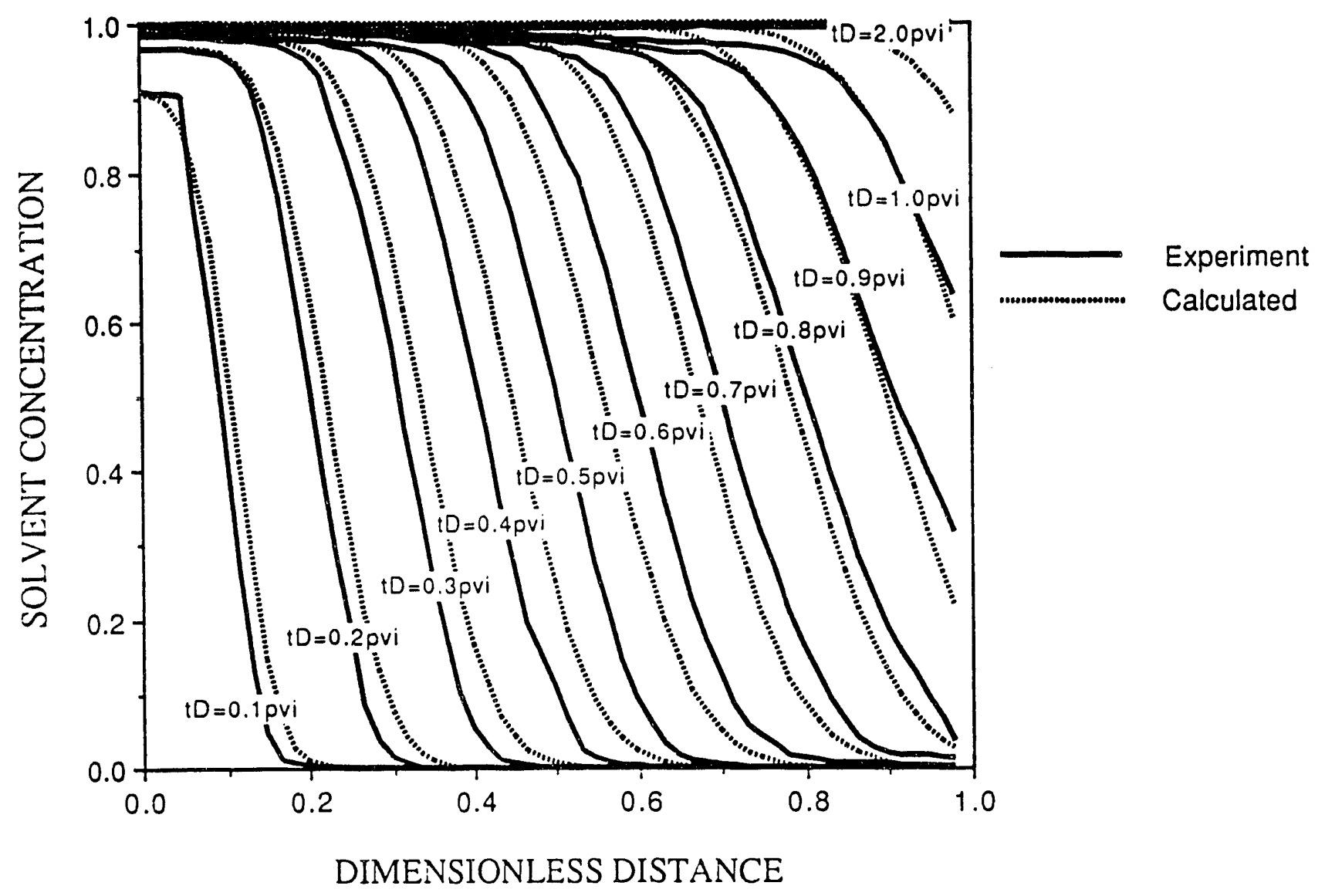

Figure 6. Experimental Versus Computed Solvent Concentration Profiles for Tracer Test in a Berea Sandstone. $D_{L}=600 \times 10^{-5} \mathrm{~cm}^{2} / \mathrm{s}, \mathrm{R}_{\mathrm{f}}=1.00$ 


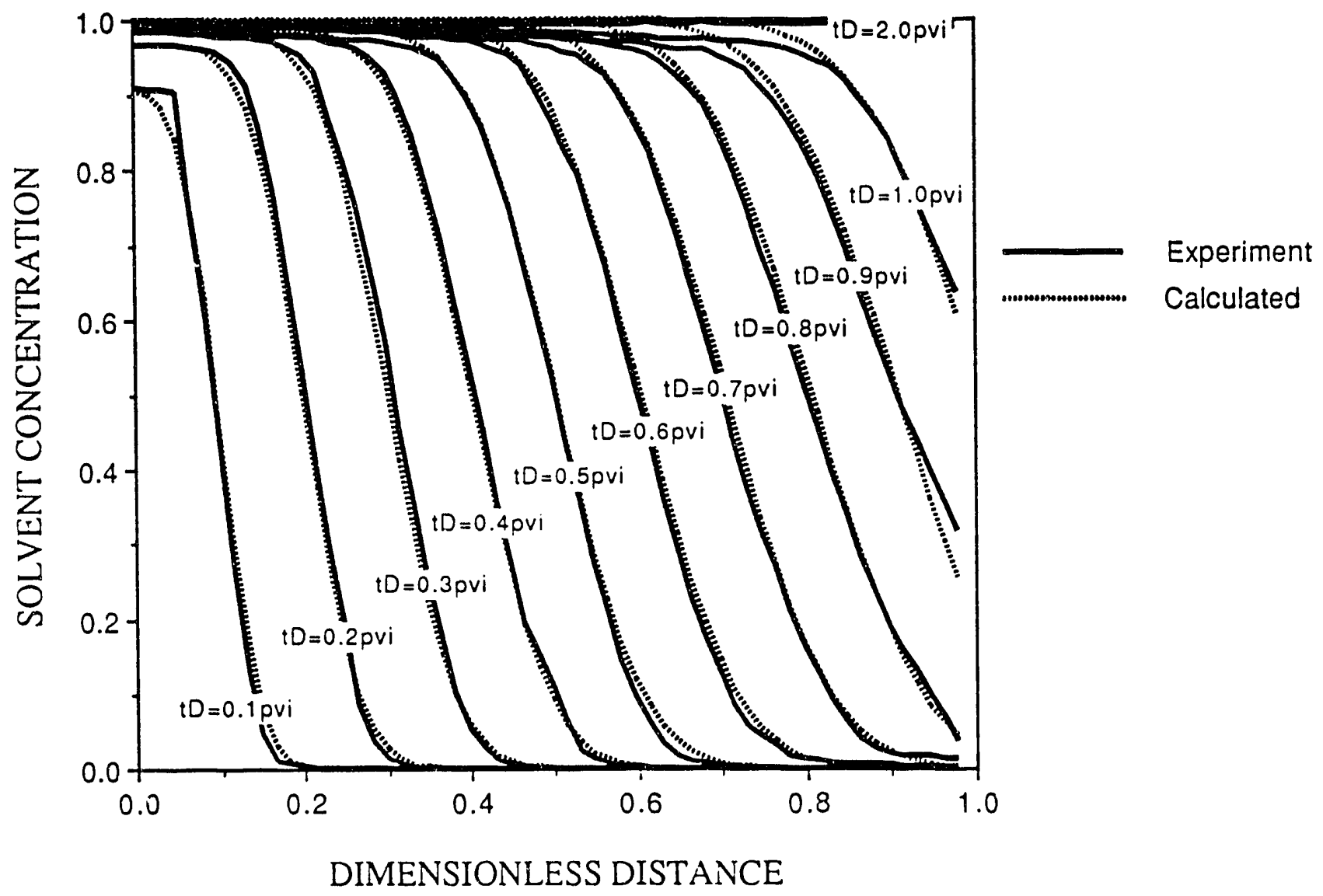

Figure 7. Experimental Versus Computed Solvent Concentration Profiles for Tracer Test in a Berea Sandstone. $D_{\mathrm{L}}=600 \times 10^{-5} \mathrm{~cm}^{2} / \mathrm{s}, \mathrm{R}_{\mathrm{f}}=1.11$ 


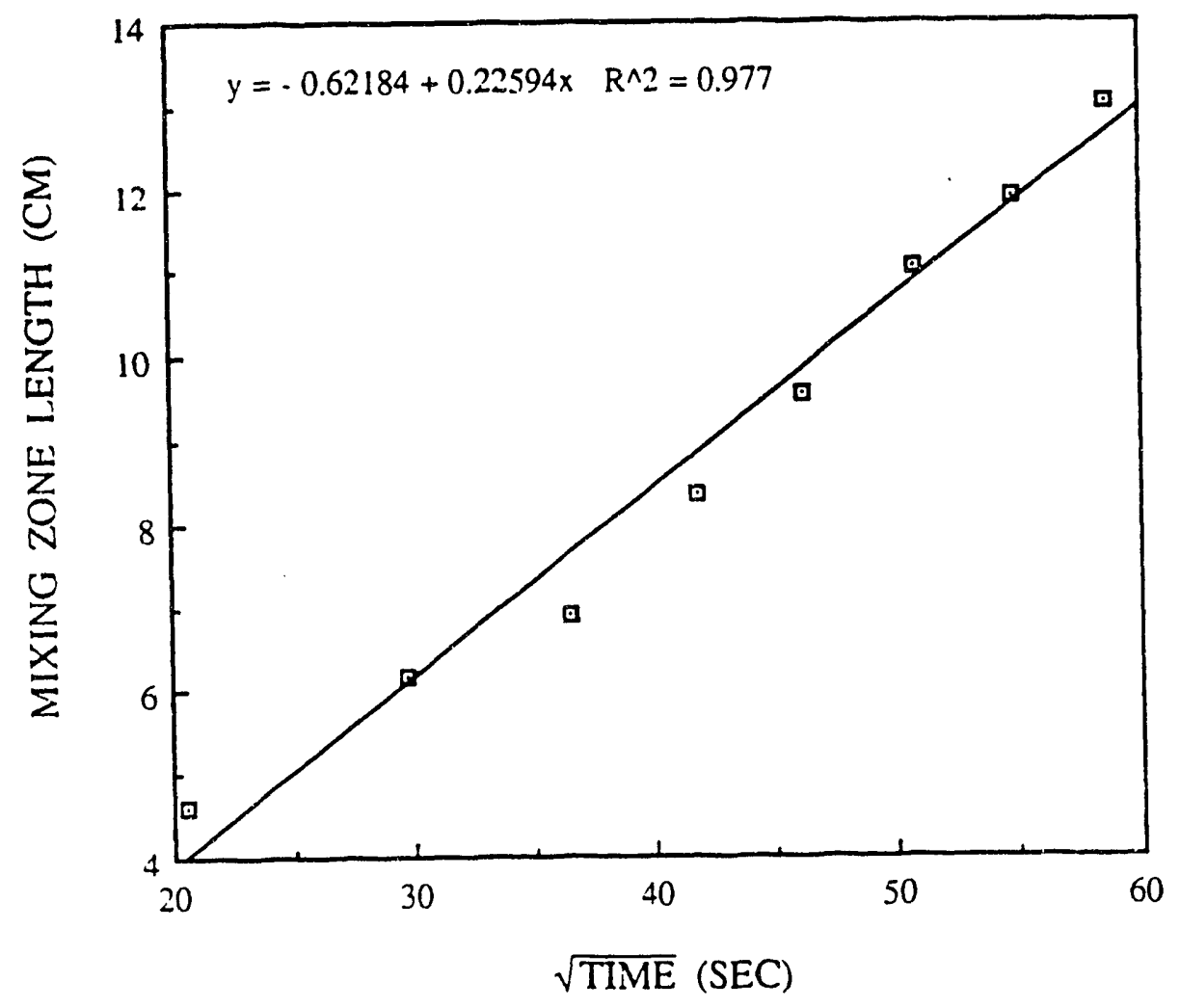

Figure 8. Growth of Mixing Zone Length with Time for a Tracer Test in a Berea Sandstone 


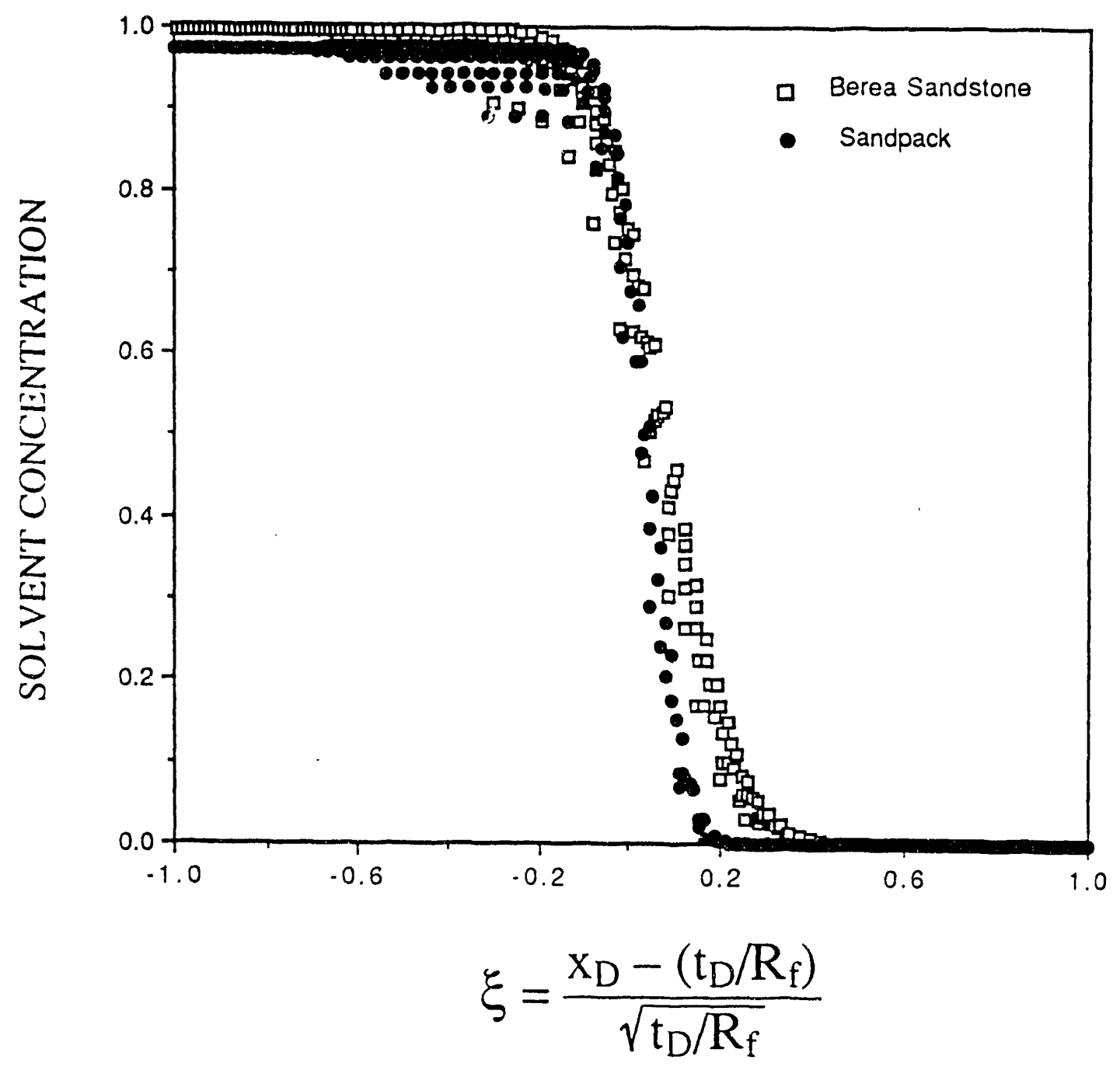

Figure 9. Similarity Transformation of Solvent Concentration Profiles for Tracer Tests in a Sandpack and a Berea Sandstone. 

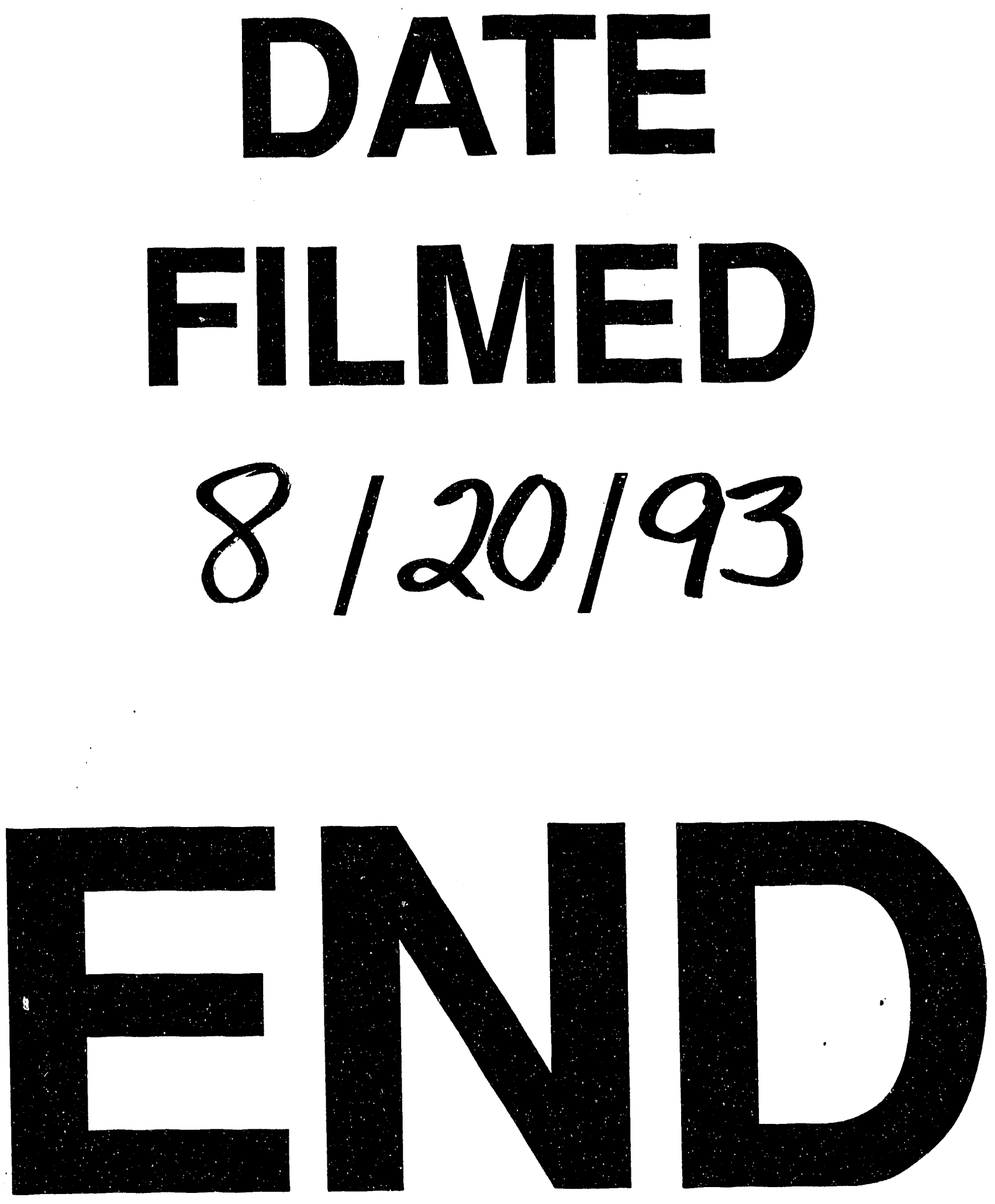


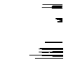

